\title{
Gestational age specific anthropometric postnatal percentile charts for neonates born at tertiary hospital in Eastern Nepal
}

\author{
Anjum Shakya ${ }^{1}$, Nisha Keshary Bhatta1,2, Rupa Rajbhandari Singh ${ }^{1,2}$, Shankar Prasad Yadav ${ }^{1,3^{*}}$ and \\ Jitendra Thakur ${ }^{1}$
}

\begin{abstract}
Background and objectives: Birth weight, Head circumference $(\mathrm{HC})$, and Length are important clinical indicators for evaluation of prenatal growth and identification of neonates requiring detail assessment and monitoring. Gestational age-specific percentile charts are essential tool for both obstetricians and pediatricians in their day to day practice. This study aimed to develop gestational age specific percentile chart of Birth weight, Length and HC for neonates.

Methods: In this Cross sectional observational study, HC, Birth weight and Length of live singleton neonates from 28 to 42 weeks of gestation fulfilling the inclusion criteria were measured over a period of one year. Mean, standard deviation, and percentiles values for different gestational age were calculated. Graphs were constructed using two way graph and Lowess smoothening method.

Results: Of total 2662 neonates, male: female ratio was 1.3:1 with maximum neonates in 40 weeks of gestation. The mean Birth weight, $\mathrm{HC}$ and Length was $2852.02 \mathrm{gm}, 33.6$ and $48.42 \mathrm{~cm}$ respectively. Overall males have more mean weight than females by $46.35 \mathrm{gms}$. However, mean HC of male and female were similar 33.6 and $33.61 \mathrm{~cm}$ respectively and on average males were $0.27 \mathrm{~cm}$ longer compared to female. The mean Birth weight, $\mathrm{HC}$ and Length at 40 weeks was $3123.43 \mathrm{gm}( \pm 427.82), 34.249 \mathrm{~cm}( \pm 0.87)$ and $49.61 \mathrm{~cm}( \pm 1.85)$ respectively. The $10^{\text {th }}, 50^{\text {th }}$ and $90^{\text {th }}$ percentile at 40 weeks for Birth weight being $2550 \mathrm{gm}, 3100 \mathrm{gm}$ and $3750 \mathrm{gm}$ respectively. The gestational age specific percentile chart and growth curve are appropriately placed in the manuscript.
\end{abstract}

Conclusions: The percentile charts in this study may be used as reference for local population and similar data from various parts of the nation can provide a national reference curve for healthy neonates.

Keywords: Percentile charts, Birth weight, Head circumference, Length, Nepal

\section{Background}

The neonatal anthropometric indicators - birth weight, length and head circumference $(\mathrm{HC})$ are of utmost importance for evaluation of prenatal growth and identification

*Correspondence: shankardharan@gmail.com

${ }^{3}$ Department of Pediatrics and Adolescent Medicine, BPKIHS, Dharan, Nepal

Full list of author information is available at the end of the article of infants that require thorough assessment and close monitoring postnatally.

Birth weight is also a valuable indicator of maternal health, nutrition and quality of antenatal services, and for the monitoring of epidemiological outcomes and public health care policies $[1,2]$. Neonatal outcome of babies with different gestation varies despite of similar weight [3].

Similarly, long infants are at higher risk of perinatal mortality, and excessive variation in $\mathrm{HC}$ can denote 
malformation of the central nervous system secondary to genetic or chromosomal abnormalities or teratogenic insults $[4,5]$.

Based on ethnically mixed population in Colorado, the first gestational age specific anthropometric reference chart was developed by Lubchenco, et al. in 1963, which is still used in many centers [6]. These centile reference charts are used to monitor clinical measurements on individuals in the context of population values [7]. However, these charts are not universally applicable because the growth potential of the fetus is influenced by various factors including sex of the infant, ethnic group and geographical factors [8]. Changes in the parity, socioeconomic and environmental conditions necessitate an update in the existing growth charts.

Similar growth charts have been published by various authors representing growth patterns of diverse population in different parts of the world. The objective of present study is to construct percentile charts for birth weight, length and head circumference for infants born from 28 to 42 weeks of gestation to suit the neonatal population of Nepal.

\section{Method}

This study was a cross-sectional observational study conducted over a period of one year (August 2015 to July 2016) at a tertiary center, Bishweshwar Prasad Koirala Institute of Health Sciences (BPKIHS), Dharan, Nepal. All the singleton live birth from 28 to 42 weeks of gestation within $24 \mathrm{~h}$ of birth, delivered during the study period were included in the study by consecutive nonpurposive sampling method. The ethical approval was taken from the Institutional Review Committee (IRC) of BP Koirala Institute of Health Sciences.

Gestational age was estimated by first day of the last menstrual period (LMP). In cases where LMP was unknown or in clinically discrepant cases, it was confirmed by clinical assessment using New Ballard's scoring system or first trimester ultrasonography (USG). The gestational age estimated by scoring was included if the difference between LMP and scoring was more than two weeks.

Birth weight was measured within $24 \mathrm{~h}$ of birth after drying without clothing on the electronic weighing machine EBSA-20 to the nearest $\pm 5 \mathrm{~g}$ with maximum up to $20 \mathrm{~kg}$ and calibrated before each measurement.

Length was recorded placing the child supine to the nearest $0.1 \mathrm{~cm}$ using infantometer. The head was held firmly in position against a fixed upright head board by one person. Legs were kept straight, keeping feet at right angles brought into firm contact with the child's heels.

Head Circumference was measured at 24 to $48 \mathrm{~h}$ of life with the locally available non-stretchable measuring tape, the maximum circumference of the head from the occipital protuberance to the supraorbital ridges on the forehead to the nearest $0.1 \mathrm{~cm}$ was recorded.

Name of mother, birth weight, length and $\mathrm{HC}$ of enrolled newborn were recorded. Multiple birth, gross congenital malformations and hydrops, still birth, maternal complications (e.g. Pre-eclampsia/ eclampsia, Gestational Diabetes Mellitus (GDM), severe anemia, maternal medical disorders.), large caput succedaneum and cephalhaematoma were excluded.

Data entry was done in Microsoft 2007 Excel. Data analysis was performed in Microsoft 2007 Excel and Stata IC 14.1. The percentiles $\left(3^{\text {rd }}, 10^{\text {th }}, 25^{\text {th }}, 50^{\text {th }}, 75^{\text {th }}\right.$, $90^{\text {th }}, 95^{\text {th }}$, and $97^{\text {th }}$ ) for the birth weight, length and HC according to gestational age was calculated, and charts constructed using Stata IC 14.1 Growth curves were constructed using two way graph and Lowess smoothening method.

\section{Results}

Out of 2662 live singleton normal newborns included in the study, 1520 were male and 1142 were female with male: female ratio of $1.3: 1$. The maximum neonates $(\mathrm{n})$ were in 40 weeks of gestation (Fig. 1).

The mean birth weight for this study population was $2852.02 \mathrm{gm}( \pm 571.89)$. Mean birth weight of male was $2871.9 \mathrm{gm}( \pm 600.78)$ and of female was $2825.55 \mathrm{gm}$ $( \pm 530.13)$. Similarly, mean length of male newborn was $48.52 \mathrm{~cm}( \pm 2.64)$ and of female newborn was $48.25 \mathrm{~cm}$ $( \pm 2.25)$. On an average male newborn length was $0.27 \mathrm{~cm}$ more than female newborn. The mean head circumference of the newborn was $33.6 \mathrm{~cm}$ and both male and female newborn had the similar mean head circumference.

According to gestational age of newborn, the mean \pm SD of birth weight, head circumference and length were calculated (Table 1).

The $50^{\text {th }}$ percentile for birth weight, $\mathrm{HC}$ and length for neonates at 40 weeks of gestation were $3100 \mathrm{gm}, 34.2$ and $49.8 \mathrm{~cm}$ respectively. The gestational age specific percentile of different anthropometric variables are shown in Tables 2,3 and 4.

Growth curves are shown in Figs. 2, 3 and 4.

\section{Discussion}

BPKIHS is the tertiary care hospital in Eastern Nepal with highest number of deliveries. It includes mixed group of population that represents different ethnicity, races and castes. Data on birth weight indicates important role of geographic location as an environmental factor on fetal growth. This signifies that regional individualized growth charts for each population is an ideal method for evaluation $[9,10]$. Hence, construction of 


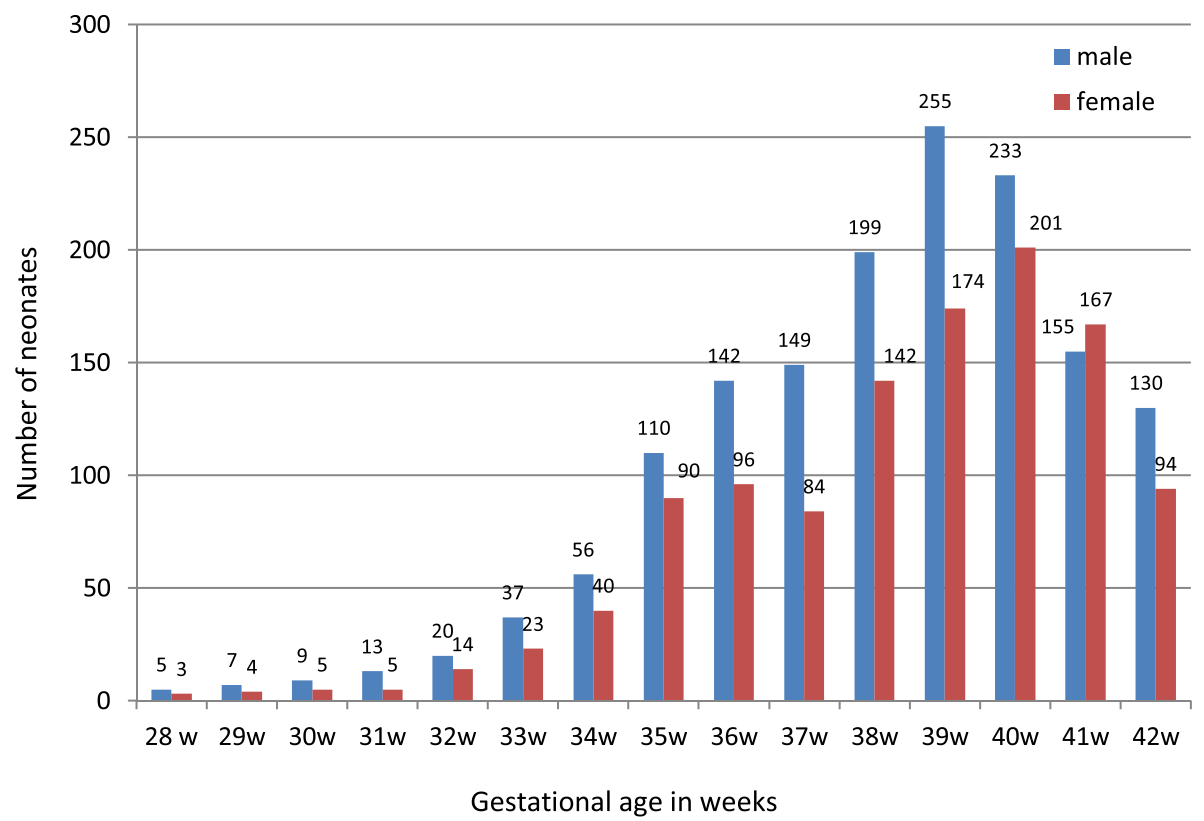

Fig. 1 Gender wise distribution of neonates according to gestational age

Table 1 Mean birth weight, head circumference and length of neonates according to gestational age

\begin{tabular}{lccc}
\hline $\begin{array}{l}\text { Gestational } \\
\text { age (in } \\
\text { weeks) }\end{array}$ & $\begin{array}{l}\text { Mean weight } \pm \text { (in grams) } \\
\text { SD }\end{array}$ & $\begin{array}{l}\text { Mean HC } \pm \text { SD } \\
\text { (in centimeter) }\end{array}$ & $\begin{array}{l}\text { Mean length } \pm \text { SD } \\
\text { (in centimeter) }\end{array}$ \\
\hline 28 & $1131.25 \pm 186.96$ & $26.75 \pm 1.41$ & $36.98 \pm 3.81$ \\
29 & $1563.64 \pm 423.14$ & $29.59 \pm 2.49$ & $43.65 \pm 2.47$ \\
30 & $1535.71 \pm 332.49$ & $29.16 \pm 3.87$ & $42.49 \pm 3.87$ \\
31 & $1561.11 \pm 325.2$ & $29.58 \pm 1.71$ & $43.88 \pm 1.8$ \\
32 & $1717.94 \pm 365.91$ & $29.26 \pm 1.76$ & $43.99 \pm 2.97$ \\
33 & $1848.33 \pm 377.32$ & $30.66 \pm 1.54$ & $44.21 \pm 2.16$ \\
34 & $2251.04 \pm 438.96$ & $32.03 \pm 1.73$ & $45.95 \pm 1.74$ \\
35 & $2328.23 \pm 373.77$ & $32.6 \pm 1.71$ & $46.42 \pm 1.49$ \\
36 & $2594.45 \pm 445.56$ & $33.19 \pm 1.21$ & $47.24 \pm 1.69$ \\
37 & $2730.9 \pm 427.62$ & $33.48 \pm 1.17$ & $47.9 \pm 1.86$ \\
38 & $2971.03 \pm 396.99$ & $33.92 \pm 1.03$ & $49.09 \pm 1.86$ \\
39 & $3057.76 \pm 403.05$ & $34.133 \pm 0.9$ & $49.29 \pm 1.79$ \\
40 & $3123.43 \pm 427.82$ & $34.249 \pm 0.87$ & $49.61 \pm 1.85$ \\
41 & $3193.39 \pm 398.09$ & $34.406 \pm 0.83$ & $49.85 \pm 1.76$ \\
42 & $3136.83 \pm 442.43$ & $34.328 \pm 0.72$ & $49.22 \pm 1.72$ \\
\hline
\end{tabular}

percentile charts for this population prepared according to the features advised by WHO would create ideal reference for the country [11].

A WHO multicenter study reported that the average birth weight of Nepalese newborns was 2780 gms [12]. Our study has shown higher overall mean birth weight (2852.02 gms) as compared to WHO study. The mean birth weight at 40 weeks of gestation was 3123.43gms which was similar to a study done by Manandhar et al. in a tertiary care hospital in Kathmandu who has reported it as 3100 gms [13] and higher than the report of Aryal et al. where mean birth weight of babies at 40 weeks was 3023 gms [3]. This mean birth weight was much higher than that of other countries of this region where the studies from Bangladesh reported it as $2679.0 \pm 431.43$ to $2,889 \pm 468$ gms [14, 15] and of India 2666 to $2945 \pm 516$ gm $[16,17]$. As we have not studied maternal factors affecting birth weight like socioeconomic status, consanguinity, gravida status and paternal factors, it would be difficult to explain the difference in mean birth weights between these studies.

The mean head circumference of neonates in our study was $33.6 \pm 1.55 \mathrm{~cm}$, with male and female neonates having $\mathrm{HC}$ of $33.6 \pm 1.67 \mathrm{~cm}$ and $33.61 \pm 1.38 \mathrm{~cm}$ respectively which is lower in overall $(36.55 \pm 1.189 \mathrm{~cm})$ as well as both male $(36.57 \pm 4.60 \mathrm{~cm})$ and female $(36.54 \pm 4.67 \mathrm{~cm})$ compared to study done in Western Rajasthan [10]. The neonates included in the above study included only term neonates from gestational age of 37-42 weeks which could be the cause for higher $\mathrm{HC}$ compared to our study. However at 40 weeks of gestation the mean $\mathrm{HC}$ in study our study was $34.25 \pm 0.87 \mathrm{~cm}$ which is similar to Manandhar et al. of $34 \pm 1.2 \mathrm{~cm}$ but much higher than that by Aryal et al. and Lubchenco et al. which were $33.61 \pm 1.52$ and $33.8 \mathrm{~cm}$ respectively $[3,6,13]$. Similarly, In a study done in British Columbia, the mean head circumference of male $34.70 \pm 1.64 \mathrm{~cm}$ was higher than that of females 
Table 2 Percentile values of birth weight (grams) for each gestation from 28 to 42 weeks

\begin{tabular}{|c|c|c|c|c|c|c|c|}
\hline $\begin{array}{l}\text { Gestational age (in } \\
\text { weeks) }\end{array}$ & $3^{\text {rd }}$ & $10^{\text {th }}$ & $25^{\text {th }}$ & $50^{\text {th }}$ & $75^{\text {th }}$ & $90^{\text {th }}$ & $97^{\text {th }}$ \\
\hline 28 & 950 & 950 & 950 & 1125 & 1287 & 1330 & 1379 \\
\hline 29 & 1150 & 1160 & 1250 & 1400 & 2000 & 2050 & 2330 \\
\hline 30 & 1000 & 1100 & 1250 & 1500 & 1825 & 2025 & 2030. \\
\hline 31 & 1200 & 1245 & 1300 & 1500 & 1712. & 2205 & 2224. \\
\hline 32 & 1231 & 1275 & 1500 & 1675 & 1825 & 2250 & 2795 \\
\hline 33 & 1207. & 1500 & 1612. & 1800 & 2000 & 2195 & 2877. \\
\hline 34 & 1432 & 1720 & 2000 & 2250 & 2400 & 2800 & 3500 \\
\hline 35 & 1500 & 1910 & 2162. & 2350 & 2500 & 2745 & 3248. \\
\hline 36 & 1755. & 2000 & 2300 & 2600 & 2850 & 3205 & 3500 \\
\hline 37 & 2000 & 2100 & 2500 & 2750 & 3000 & 3280 & 3500 \\
\hline 38 & 2250 & 2500 & 2700 & 3000 & 3250 & 3500 & 3750 \\
\hline 39 & 2445 & 2500 & 2750 & 3000 & 3250 & 3600 & 3900 \\
\hline 40 & 2300 & 2550 & 2800 & 3100 & 3462 & 3750 & 3947. \\
\hline 41 & 2500 & 2750 & 2900 & 3200 & 3450 & 3750 & 4065. \\
\hline 42 & 2300 & 2500 & 3862. & 3150 & 3300 & 3750 & 4012. \\
\hline
\end{tabular}

Table 3 Percentile values of head circumference (centimeter) for each gestation from 28 to 42 weeks

\begin{tabular}{|c|c|c|c|c|c|c|c|}
\hline $\begin{array}{l}\text { Gestational age (in } \\
\text { weeks) }\end{array}$ & $3^{\text {rd }}$ & $10^{\text {th }}$ & $25^{\text {th }}$ & $50^{\text {th }}$ & $75^{\text {th }}$ & $90^{\text {th }}$ & $97^{\text {th }}$ \\
\hline 28 & 25.7 & 25.7 & 25.9 & 26.5 & 28.6 & 28.6 & 28.8 \\
\hline 29 & 26.4 & 26.5 & 27 & 29.8 & 32 & 32.8 & 33 \\
\hline 30 & 25.5 & 26 & 27.5 & 28.6 & 31.1 & 32.1 & 32.6 \\
\hline 31 & 27 & 27 & 28.2 & 29.4 & 30.8 & 32.1 & 32.5 \\
\hline 32 & 27 & 27 & 27.9 & 29 & 30.5 & 32.1 & 32.7 \\
\hline 33 & 27 & 28.8 & 30 & 31 & 31.7 & 32 & 33.9 \\
\hline 34 & 27 & 29.9 & 31.2 & 32 & 33.2 & 33.8 & 34.5 \\
\hline 35 & 30 & 31.5 & 32 & 33 & 33 & 33.9 & 34.3 \\
\hline 36 & 30 & 31.5 & 32.6 & 33.5 & 34 & 34.5 & 34.88 \\
\hline 37 & 30.8 & 32.1 & 33 & 33.7 & 34.2 & 34.7 & 35 \\
\hline 38 & 32 & 33 & 33.4 & 34 & 34.5 & 35 & 35.4 \\
\hline 39 & 32 & 33 & 33.6 & 34.1 & 34.7 & 35.3 & 35.6 \\
\hline 40 & 32.5 & 33.2 & 33.8 & 34.2 & 34.8 & 35.4 & 36 \\
\hline 41 & 32.8 & 33.5 & 34 & 34.4 & 35 & 35.4 & 36 \\
\hline 42 & 32.8 & 33.4 & 34 & 34.4 & 34.7 & 35 & 35.8 \\
\hline
\end{tabular}

$34.13 \pm 1.52 \mathrm{~cm}$ which was higher in both gender as compared to our study [18].

Birth length at 40 weeks of gestation was found to be similar in our study $(49.61 \pm 1.85 \mathrm{~cm})$ compared with that of Aryal et al. (49.22 $\pm 1.52 \mathrm{~cm})$, Lubchenco et al. (49.4) and Manandhar et al. $(49.2 \pm 2.2 \mathrm{~cm})$ [3, 6, 13]. Similarly, males $(51.98 \pm 2.84 \mathrm{~cm})$ were longer than females $(51.23 \pm 2.72 \mathrm{~cm})$ similar to our study but with lower mean value [18].

In comparison to our data with that of Lubchenco, et al. suggests that the 10th and 90th centiles of our neonates are lower. This resulted in overestimation of the incidence of SGA and underestimation of LGA babies, leading to many AGA neonates labelled as SGA, and LGA neonates being overlooked as they are falsely classified as appropriate for gestational age (AGA). This highlights the importance of population specific and updated growth charts.

The limitations of the study are the gestational age of the neonates were not ultrasonography based but rather mostly based on LMP which may have error due to various factors like educational status of 
Table 4 Percentile values of length (centimeter) for each gestation from 28 to 42 weeks

\begin{tabular}{|c|c|c|c|c|c|c|c|}
\hline $\begin{array}{l}\text { Gestational age (in } \\
\text { weeks) }\end{array}$ & $3^{\text {rd }}$ & $10^{\text {th }}$ & $25^{\text {th }}$ & $50^{\text {th }}$ & $75^{\text {th }}$ & $90^{\text {th }}$ & $97^{\text {th }}$ \\
\hline 28 & 34 & 34 & 34.9 & 35.6 & 37.5 & 42.3 & 42.4 \\
\hline 29 & 38 & 38.8 & 42.8 & 43.3 & 45.6 & 46.5 & 46.7 \\
\hline 30 & 33 & 35 & 40.3 & 44 & 45.5 & 45.7 & 46 \\
\hline 31 & 41 & 41 & 42.8 & 43.4 & 45.7 & 46.2 & 46.8 \\
\hline 32 & 35.9 & 39.5 & 42 & 44.5 & 46.1 & 47.9 & 48.7 \\
\hline 33 & 38.1 & 42.6 & 43.5 & 44 & 45 & 46.2 & 48.2 \\
\hline 34 & 42.6 & 44 & 45 & 45.9 & 46.7 & 48 & 49.9 \\
\hline 35 & 43.6 & 45 & 46 & 46 & 47 & 48 & 49.3 \\
\hline 36 & 43.8 & 45.5 & 46 & 47 & 48.5 & 49.6 & 50.8 \\
\hline 37 & 44 & 45.8 & 46.8 & 47.8 & 49 & 50.2 & 51.3 \\
\hline 38 & 46 & 46.9 & 47.5 & 49 & 50.5 & 51.6 & 52.4 \\
\hline 39 & 46.4 & 46.9 & 48 & 49.1 & 50.8 & 51.6 & 52.5 \\
\hline 40 & 46 & 47 & 48 & 49.8 & 51 & 51.8 & 52.8 \\
\hline 41 & 46.8 & 47.3 & 48.5 & 50 & 51 & 52 & 53 \\
\hline 42 & 46 & 46.8 & 48 & 49.2 & 50.2 & 51.2 & 52.5 \\
\hline
\end{tabular}

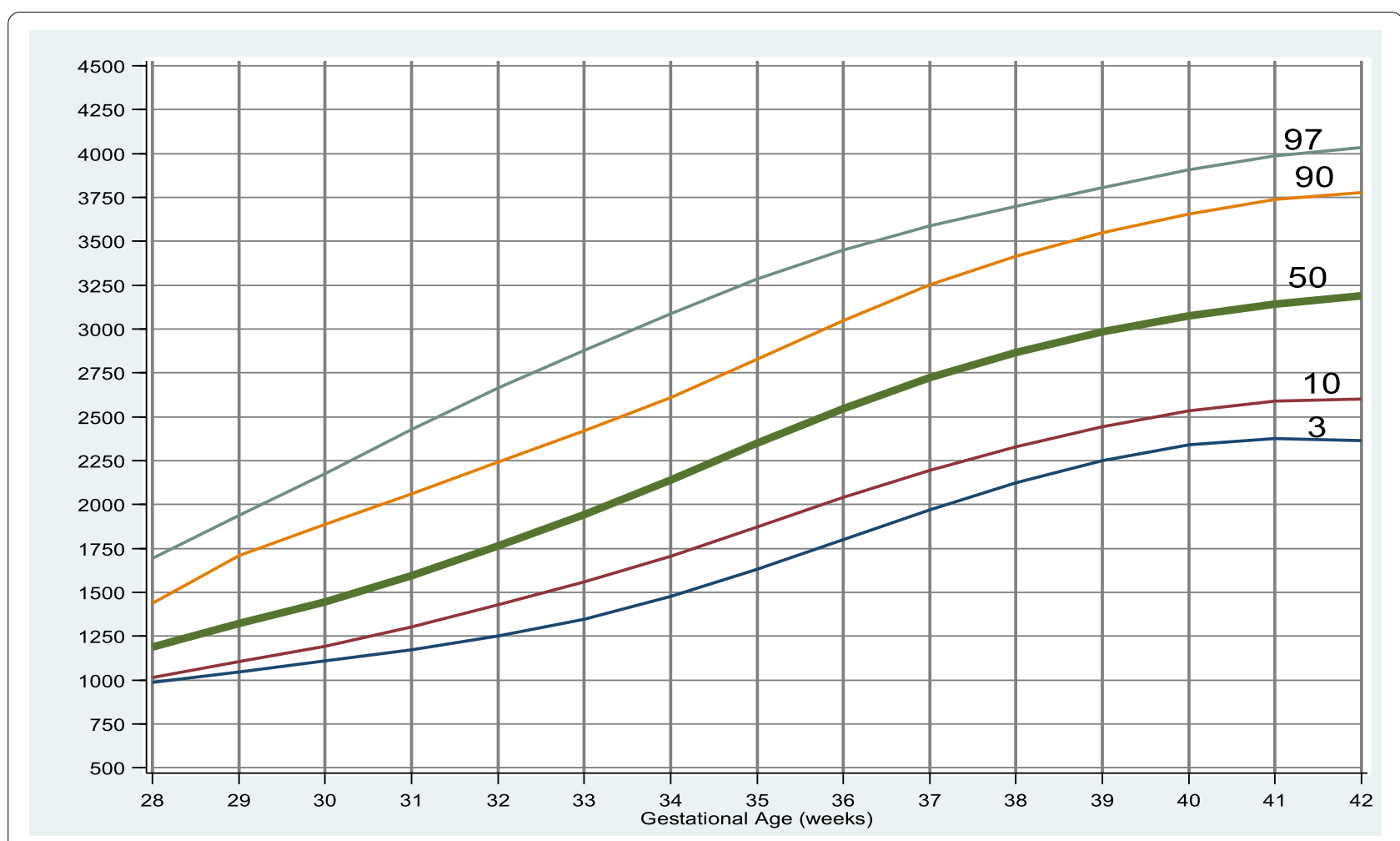

Fig. 2 Gestational age specific percentile curve for birth weight

mother leading to under or over estimation of gestational age. The numbers of preterm infants were less in number similar to other studies. Factors other than ethnicity like altitude, maternal size, parity, smoking, parental social position which can affect fetal growth could confound the ethnic differences which has been observed in numerous other studies were not analyzed in detail and lastly it was a single centered study. 


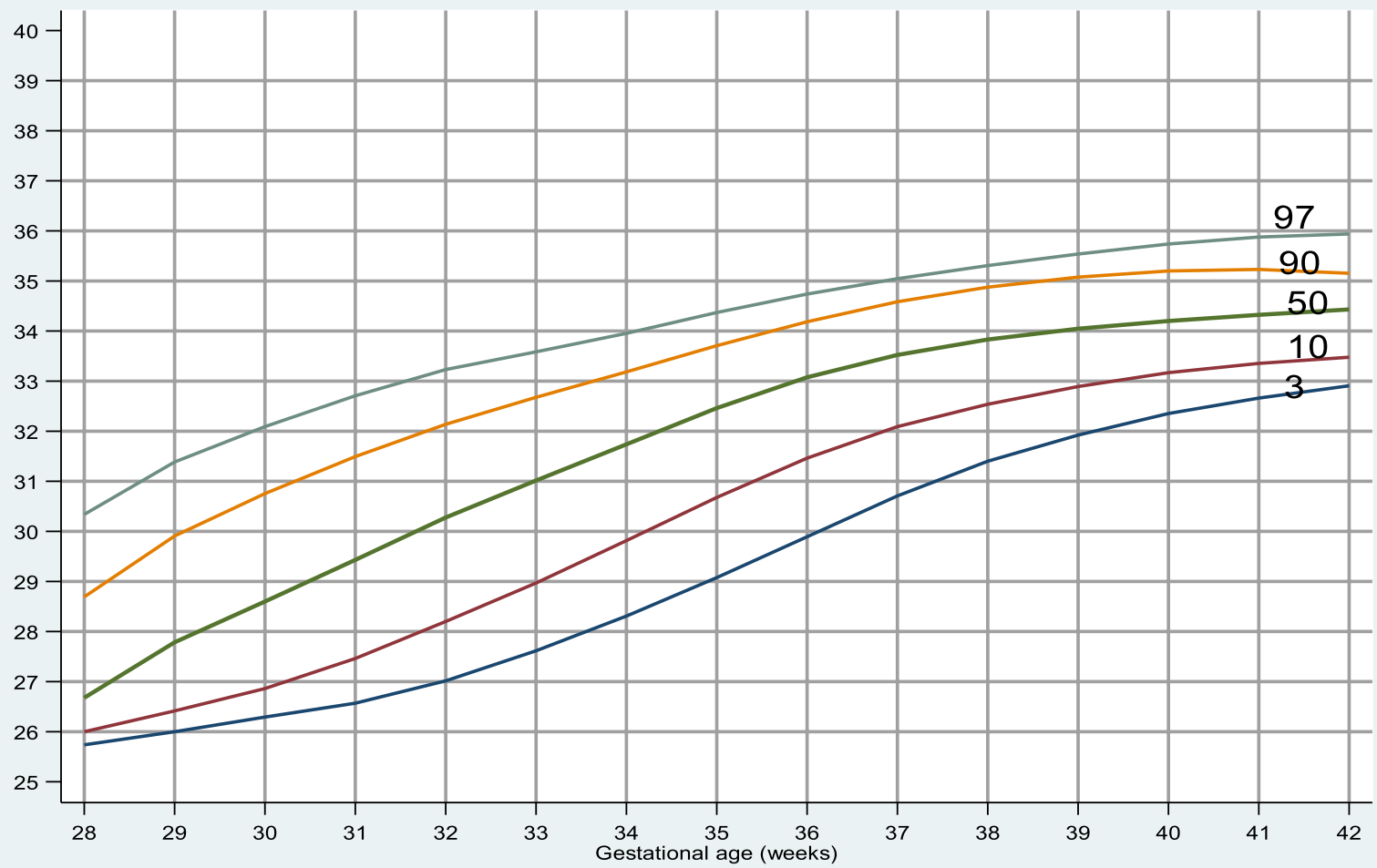

Fig. 3 Gestational age specific percentile curve for head circumference

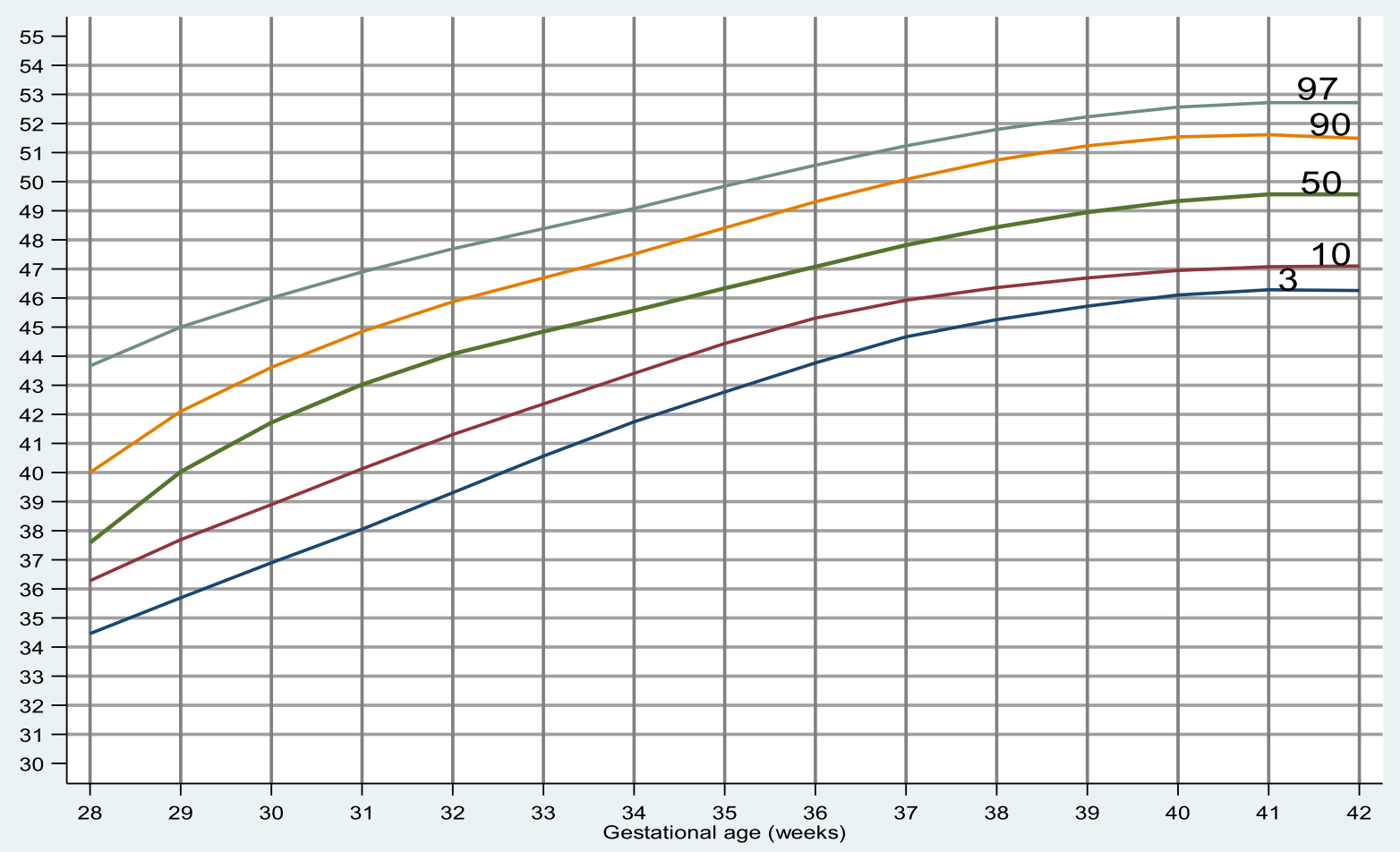

Fig. 4 Gestational age specific percentile curve for length 


\section{Conclusions}

The study concluded that the mean birth weight, head circumference and length of the single live neonates from 28 to 42 weeks of gestation was $2852.02 \pm 571.89$ gms, $33.6 \pm 1.55 \mathrm{~cm}$ and $48.42 \pm 2.48 \mathrm{~cm}$ respectively.

In this study, we have established local relevant gestational age specific percentile chart and growth curves for Birth weight, Head circumference and length which might be appropriate for babies born in this region.

\section{Abbreviations}

AGA: Appropriate for Gestational Age; BPKIHS: Bishweshwar Prasad Koirala Institute of Health Sciences; GDM: Gestational Diabetes Mellitus; HC: Head Circumference.; IRC: Institutional Review Committee; LGA: Large for Gestational Age; LMP: Last Menstrual Period; SD: Standard Deviation; SGA: Small for Gestational Age; USG: Ultrasonography; WHO: World Health Organization.
\end{abstract}

\section{Acknowledgements}

I would like to acknowledge Dr. Ohmar Man Pradhan, Dr. Pradeep Shrestha and Satya Bhama Shrestha for guidance and helping with the computer works.

\section{Authors' contributions}

AS: concept and design, drafting of article, data collection, final approval of the article. NKB and SPY: design, drafting of article, data analysis of article. RRS and JT: design, drafting of article. All authors read and approved the final manuscript.

\section{Funding}

There was no funding from any organization or person.

\section{Availability of data and materials}

The dataset used and/ or analyzed during the current study are available from the corresponding author on reasonable request.

\section{Declarations}

\section{Ethics approval and consent to participate}

Ethical clearance was obtained from Institutional Review Committee (IRC) IRC/593/015 of BP Koiral Institute of Health Sciences.

Informed consent was obtained from parents of allparticipants.

All methods were carriedout in accordance with relevant guidelines and regulations.

\section{Consent for publication}

Informed assent was taken from Parents. Confidentiality of data was maintained.

\section{Competing interests}

The authors declare that they have no competing interests.

\section{Author details}

${ }^{1}$ Department of Pediatrics, B.P.Koirala Institute of Health Sciences, Dharan, Nepal. ${ }^{2}$ Division of Neonatology, Department of Pediatrics and Adolescent Medicine, BPKIHS, Dharan, Nepal. ${ }^{3}$ Department of Pediatrics and Adolescent Medicine, BPKIHS, Dharan, Nepal.

Received: 16 March 2021 Accepted: 16 December 2021

Published online: 15 February 2022

\section{References}

1. Kumar V, Deshmukh PR, Taywade M, Gupta SS. Magnitude and correlates of low birth weight at term in rural Wardha, Central India. Online J Heal Allied Scs. 2016;15(1):2.
2. KHENG GOHS. Birthweight percentiles bygestational age and maternal factors that affect birthweight in Singapore. 2011.

3. Aryal DR, Gurung R, Misra S, Khanal P, Pradhan A, Gurubacharya SM. Intrauterine growth curves forsingleton live babies in Paropakar maternity and women's hospital in Nepal. J Nepal Health Res Counc. 2012;10(21):160-6.

4. Oluwafemi O, Njokanma F, Disu E, Ogunlesi T. The current pattern of gestational age-related anthropometric parameters of term Nigerian neonates. S Afr J Child Health. 2013;7(3):100-4.

5. Fok TF, So HK, Wong E, Ng PC, Chang A, Lau J, et al. Updated gestational age specific birth weight, crown-heel length, and head circumference of Chinese newborns. Arch Dis Childhood-Fetal Neonatal Ed. 2003;88(3):F229-36.

6. Lubchenco LO, Hansman C, Dressler M, Boyd E. Intrauterine growth as estimated from liveborn birth-weight data at 24 to 42 weeks of gestation. Pediatrics. 1963;32(5):793-800.

7. Bonellie S, Chalmers J, Gray R, Greer I, Jarvis S, Williams C. Centile charts for birthweight for gestational age for Scottish singleton births. BMC Pregnancy Childbirth. 2008;8(1):5.

8. Kandraju H, Agrawal S, Geetha K, Sujatha L, Subramanian S, Murki S. Gestational age-specific centile charts for anthropometry at birth for south Indian infants. Indian Pediatr. 2012;49(3):199-202. https://doi.org/ 10.1007/s13312-012-0060-2.

9. Das UG, Sysyn GD. Abnormal fetal growth: intrauterine growth retardation, small for gestational age, large for gestational age. Pediatr Clin North Am. 2004;51(3):639-54, viii. https://doi.org/10.1016/j.pcl.2004.01.004.

10. Kataria SK, Gaur S. An anthropometric study of normal full term newborns at birth in western Rajasthan. Int J Adv Res. 2014;2(10):671-5.

11. Ulijaszek SJ. Between-population variation in pre-adolescent growth. Eur J Clin Nutr. 1994;48(Suppl 1):S5-13; discussion S13-4. Available from: http://europepmc.org/abstract/MED/8005091.

12. World Health Organization. Regional Office for South-East Asia. Multicentre study of low birth weight and infant mortality in India, Nepal and Sri Lanka. WHO Regional Office for South-East Asia. 1994. https://apps.who. int/iris/handle/10665/205542.

13. Manandhar SR, Manandhar DS. Gestational age specific anthropometric percentile charts of newborns at Kathmandu Medical College Teaching Hospital. J Kathmandu Med Coll. 2014;3(3):97-101.

14. Huque F, Hussain Z. Detection of low birth-weight new born babies by anthropometric measurements in Bangladesh. Indian J Pediatr. 1991;58(2):223-31. https://doi.org/10.1007/BF02751125.

15. Dhar B, Mowlah G, Nahar S, Islam N. Birth-weight status of newborns and its relationship with other anthropometric parameters in a public maternity hospital in Dhaka, Bangladesh. J Health Popul Nutr. 2002;20(1):36-41.

16. Yajnik CS, Fall CHD, Coyaji KJ, Hirve SS, Rao S, Barker DJP, et al. Neonatal anthropometry: the thin-fat Indian baby. The Pune maternal nutrition study. Int J Obes. 2003;27(2):173-80.

17. Matthews Mathai SJ, Karthikeyan NG. Birthweight standards for south Indian babies. Indian Pediatr. 1996;33:203.

18. Kierans WJ, Kendall PRW, Foster LT, Liston RM, Tuk T. New birth body length and head circumference charts for the British Columbia population. B C Med J. 2007:49(2):72-7.

\section{Publisher's Note}

Springer Nature remains neutral with regard to jurisdictional claims in published maps and institutional affiliations. 